\title{
Collection Efficiency of Metallic Contaminants on Si Wafer by Vapor-Phase Decomposition-Droplet Collection
}

\author{
Hye-Young Chung,* Young-Hun Kim,* Hyo-Yong Cho,* Bo-Young LeE,* \\ Hak-Do Yoo, ${ }^{*}$ and Sang-Hak LEE** \\ *R\&D Center, LG Siltron Inc., 283, Imsoo-dong, Kumi, Kyungbuk, 730-350, Korea \\ **Department of Chemistry, Kyungpook National University, 1370 Sankyuk-dong, Puk-gu, Taegu 702-701, Korea
}

\begin{abstract}
The collection efficiency of metallic contaminants on four different types of silicon wafers was investigated. $\mathrm{P}, \mathrm{p}^{+}, \mathrm{n}$ and $\mathrm{n}^{+}$-type polished silicon wafers were used for the substrate, and 14 metallic elements ( $\mathrm{Na}, \mathrm{Mg}, \mathrm{Al}, \mathrm{K}, \mathrm{Ca}, \mathrm{Cr}, \mathrm{Fe}, \mathrm{Mn}, \mathrm{Co}$, $\mathrm{Ni}, \mathrm{Cu}, \mathrm{Zn}, \mathrm{Mo}$ and $\mathrm{Ti}$ ) were contaminated on silicon wafer surface. Vapor-phase decomposition-droplet collection (VPD-DC) was employed as the sample preparation procedure. For the collecting solution, $\mathrm{HNO}_{3}, \mathrm{HF}$ and a mixture of $\mathrm{HF}$ and $\mathrm{H}_{2} \mathrm{O}_{2}$ were used, respectively. A liquid droplet collecting metallic contaminants during VPD-DC was analyzed by inductively coupled plasma-mass spectrometry (ICP-MS). As a result, it was found that $\mathrm{HNO}_{3}$ and $\mathrm{HF}$ were not suitable for collecting $\mathrm{Cu}$. Copper was not collected completely in $\mathrm{HNO}_{3}$ and $\mathrm{HF}$. A mixture of $\mathrm{HF}$ and $\mathrm{H}_{2} \mathrm{O}_{2}$ is the most effective to collect all of the tested metallic elements, regardless of the dopant concentration and type of substrate.
\end{abstract}

(Received November 2, 2000; Accepted January 25, 2001)

\section{Introduction}

Metallic contaminants on a wafer surface have been known to be a major source of performance failure in IC devices by increasing the $\mathrm{p}-\mathrm{n}$ junction leakage, degradation of the oxide breakdown voltage and deteriorating the carrier lifetime. ${ }^{1}$ With shrinking device geometries, the tolerance level of metallic contaminants is becoming more stringent. It has been reported that metallic contamination on a silicon surface needs to be suppressed to less than $1 \times 10^{10}$ atoms $/ \mathrm{cm}^{2}$ to manufacture a 64 Mbit DRAM in order to prevent the above-mentioned failures. ${ }^{2}$ According to device development and an estimation of the research organization, this level should be down to $1 \times 10^{9}$ atoms $/ \mathrm{cm}^{2}$ in the future. With this tendency, analytical techniques used to measure ultratrace metallic contaminants on a silicon surface have also been developed.

One of the most prevalent techniques used for measuring metallic contaminants is VPD-DC (vapor phase decompositiondroplet collection). During the VPD procedure, the wafer is exposed to hydrogen fluoride vapor in a closed container to decompose the surface oxide layer. The decomposition reaction of silicon oxide by hydrogen fluoride vapor is expressed by

$$
\mathrm{SiO}_{2}+6 \mathrm{HF} \Leftrightarrow \mathrm{H}_{2} \mathrm{SiF}_{6}+2 \mathrm{H}_{2} \mathrm{O}
$$

Metallic contaminants remain on the wafer surface after the decomposition of silicon oxide. In the DC procedure, these metallic contaminants are collected into a small amount of ultrahigh-purity liquid droplets by scanning the wafer surface. A liquid droplet prepared by VPD-DC is analyzed by different trace-element analysis techniques, such as atomic absorption spectrometry (VPD-AAS), ${ }^{3-7}$ inductively coupled plasma-mass spectrometry (VPD-ICP-MS) ${ }^{5,8-10}$ and total reflection X-ray fluorescence (VPD-TXRF). ${ }^{4,11-13}$

$\mathrm{DC}$ is a procedure used to collect and preconcentrate all impurities into liquid droplets. The composition of the collecting solution as well as the chemistry of the collected contaminants determine the collection efficiency. Morinaga et al. have reported that metallic contaminants deposit on a silicon wafer surface in a wet process depending on the type of metal element, the type of solution and the type of substrate. ${ }^{14}$ Therefore, a chemical reaction of metal at the silicon surface during VPD-DC can influence the collection efficiency of a metallic contaminant. However, there have been few reports concerning the collection efficiency of the VPD-DC procedure.

In this experiment, the collection efficiency of VPD-DC sample preparation was investigated for 14 elements $(\mathrm{Na}, \mathrm{Mg}$, $\mathrm{Al}, \mathrm{K}, \mathrm{Ca}, \mathrm{Cr}, \mathrm{Fe}, \mathrm{Mn}, \mathrm{Co}, \mathrm{Ni}, \mathrm{Cu}, \mathrm{Zn}, \mathrm{Mo}$ and $\mathrm{Ti}$ ) on four types of silicon wafers. Standard solutions containing 7 elements in each solution were intentionally contaminated on a silicon wafer surface. The contaminated area was scanned with various collecting solutions in the VPD-DC procedure and a droplet containing metallic contaminants, collected from the silicon wafer surface, was measured by ICP-MS. The collection efficiency was determined as the ratio of the collected metallic concentration to the initial contamination concentration.

\section{Experimental}

\section{Reagents and samples}

Metal standard solutions (1000 $\mu \mathrm{g} / \mathrm{mL}$, High Purity Standards, Charleston, SC, USA) of 14 elements were used for intentional contamination. A multielement stock solution $(1 \mu \mathrm{g} / \mathrm{mL}$ of each element) was prepared by mixing single-element standard solutions $(1000 \mu \mathrm{g} / \mathrm{mL}$ each). Standard solutions for contamination were further prepared by diluting a multielement stock solution with $2 \% \mathrm{HNO}_{3}$ solution. $\mathrm{HNO}_{3}(55 \%)$, HF (38\%) and $\mathrm{H}_{2} \mathrm{O}_{2}(35 \%)$ of high-purity solutions (TAMAPURE AA-10, Tama Chemicals Co., Kanagawa, Japan) were used in all of the experiments. Details on the concentration of the 
Table 1 Concentrations of the collecting solutions used in the experiments

\begin{tabular}{rrlc}
\hline & & \multicolumn{2}{l}{ Mixture of $\mathrm{HF}^{2}$ and $\mathrm{H}_{2} \mathrm{O}_{2}$} \\
\cline { 3 - 4 } $\mathrm{HNO}_{3}, \%$ & $\mathrm{HF} / \mathrm{ppm}$ & $\mathrm{HF}, \%$ & $\mathrm{H}_{2} \mathrm{O}_{2}, \%$ \\
\hline 0.1 & 50 & 0.02 & 1 \\
0.5 & 200 & 0.2 & 1 \\
1 & 1000 & 2 & 1 \\
2 & 5000 & & \\
\hline
\end{tabular}

Table 2 Operating conditions for the ICP-MS

\begin{tabular}{lc}
\hline \multicolumn{1}{c}{ Plasma condition } & Normal (Cold) \\
\hline RF power & $1100 \mathrm{~W}(600 \mathrm{~W})$ \\
RF frequency & $40.68 \mathrm{MHz}$ \\
Nebulizer type & $\mathrm{MCN} 6000$ \\
Plasma gas flow rate & $15 \mathrm{~L} / \mathrm{min}$ \\
Auxiliary gas flow rate & $1.2 \mathrm{~L} / \mathrm{min}(1.2 \mathrm{~L} / \mathrm{min})$ \\
Nebulizer gas flow rate & $05 \mathrm{~L} / \mathrm{min}(1.18 \mathrm{~L} / \mathrm{min})$ \\
Sample uptake rate & $94 \mu \mathrm{L} / \mathrm{min}$ \\
Sampler cone & Pt $(1.1 \mathrm{~mm})$ \\
Skimmer cone & Pt $(0.9 \mathrm{~mm})$ \\
Quadrupole chamber & $1 \times 10^{-5} \mathrm{Torr}$ \\
Operating pressure & \\
Quadrupole scan mode & Peak hopping \\
Ion lens voltage & Dynamic $($ Fixed $)$ \\
Dwell time/mass & $50 \mathrm{~ms}$ \\
Number of sweeps & 30 \\
Number of replicates & 10 \\
Integration time/mass & $1500 \mathrm{~ms}$ \\
Detector & ETP/AF210J \\
\hline
\end{tabular}

collecting solutions are listed in Table 1.

Samples were divided into four groups with their type. Borondoped wafers with a diameter of $200 \mathrm{~mm}$ were $\mathrm{p}$ type (resistivity $9-12 \Omega \mathrm{cm}$ ) and $\mathrm{p}^{+}$type (resistivity $0.01-0.02 \Omega$ $\mathrm{cm}$ ). An N-type wafer was a lightly phosphorous-doped wafer with a diameter of $150 \mathrm{~mm}$ and a resistivity $5-20 \Omega \mathrm{cm}$. An $\mathrm{N}^{+}$-type wafer was a heavily antimony doped wafer with a diameter of $150 \mathrm{~mm}$ and a resistivity $0.008-0.025 \Omega \mathrm{cm}$. All of the wafers were single-side polished and cleaned with modified RCA cleaning.

\section{Instrument and apparatus}

A liquid droplet containing metallic contaminants collected from a silicon surface was analyzed by an ICP-MS (Elan 6000, Perkin Elmer, Norwalk, CT, USA) equipped with a microconcentric nebulizer. The mass spectrometer was used in a peak-hopping mode. ICP was operated under a cool plasma condition for $\mathrm{K}, \mathrm{Ca}$ and $\mathrm{Fe}$ and under the typical condition for all other elements. The operating conditions for the ICP-MS are listed in Table 2.

A schematic diagram of the apparatus for contamination is shown in Fig. 1. The apparatus has four walls made with Teflon, and the top and bottom are open. An IR lamp is placed inside a Teflon box. Contamination using this apparatus was carried out in a class- 1 clean bench settled in a class-100 clean environment.

\section{Procedure}

All of the wafers were treated as a hydrophobic surface by VPD prior to use, and were mounted on the top of an apparatus
Drying over IR lamp

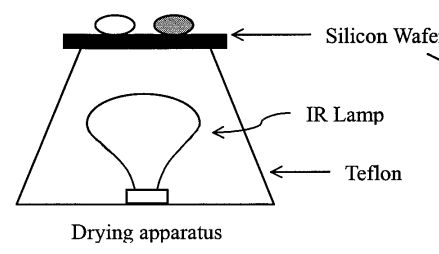

Fig. 1 Schematic diagram of the assembly used for the contamination and drying of metallic contaminants on a silicon surface.

located in the clean bench. Each $1 \mathrm{~mL}$ of standard solutions (1 $\mathrm{ng} / \mathrm{mL}$ of each element) was dropped at a different location on the polished wafer surface (Fig. 1). The standard solution for contamination was divided into two groups: group I was a mixture of $\mathrm{Na}, \mathrm{Mg}, \mathrm{Al}, \mathrm{K}, \mathrm{Ca}, \mathrm{Cr}$ and $\mathrm{Fe}$; group II contained $\mathrm{Mn}, \mathrm{Co}, \mathrm{Ni}, \mathrm{Cu}, \mathrm{Zn}, \mathrm{Mo}$ and Ti. One milliliter of a $2 \% \mathrm{HNO}_{3}$, blank solution containing no impurity was also dropped on the wafer surface to check for any unintentional contamination from the environment. Then, an IR lamp was illuminated any solution on the wafer surface dried. The contaminated wafer was cooled in air and placed in a closed container filled with HF vapor for $3 \mathrm{~min}$. Each contaminated spot was then scanned with $1 \mathrm{~mL}$ of various collecting solutions for $3 \mathrm{~min}$. The collected droplet was measured by ICP-MS. All of the experiments were carried out in a class-100 clean room.

\section{Results and Discussion}

Collection efficiency by $\mathrm{HNO}_{3}$

Figure 2 shows the collection efficiency of metallic contaminants on four types of silicon wafers by $\mathrm{HNO}_{3}$. Thirteen elements, except for $\mathrm{Cu}$, were effectively collected regardless of the concentration of $\mathrm{HNO}_{3}$. The $\mathrm{Cu}$ collection efficiency was less than $90 \%$ for all of the studied concentrations of $\mathrm{HNO}_{3}$; there was a big difference depending on the type of substrate. The $\mathrm{Cu}$ collection efficiency on $\mathrm{p}, \mathrm{n}$, and $\mathrm{n}^{+}$-type silicon wafer surfaces increased as the concentration of $\mathrm{HNO}_{3}$ was increased, while that on a $\mathrm{p}^{+}$-type wafer was almost constant regardless of the $\mathrm{HNO}_{3}$ concentration. This result is considered to have been caused by a difference in the boron doping concentration.

The following discussion concerning the difference in the $\mathrm{Cu}$ collection efficiency on the $\mathrm{p}^{+}$-type silicon surface is based on the band model reported by Seidel et al. ${ }^{15}$ According to their band model, the width of the space-charge layer on the silicon surface is shrunk sharply because of a high concentration of boron. This leads to an equivalent narrowing of the potential well, which cannot confine the electrons injected into the conduction band by the oxidation step (Eq. (2)). These injected electrons are, therefore, forced to tunnel through the spacecharge layer into a deeper region of crystal. Due to the very large hole concentration, they have a high probability of recombination with holes from the valence band.

The reaction in which silicon in an aqueous solution releases electrons can be expressed by

$$
\mathrm{Si}+2 \mathrm{H}_{2} \mathrm{O} \Leftrightarrow \mathrm{SiO}_{2}+4 \mathrm{H}^{+}+4 \mathrm{e}^{-}, E^{0}=-0.857 \text { (V vs. NHE), }
$$

where $E^{0}$ is the standard redox potential. 
(a)

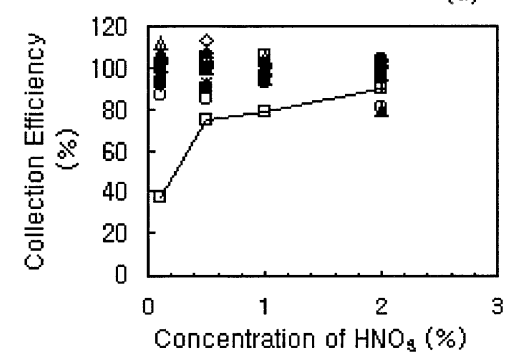

(c)

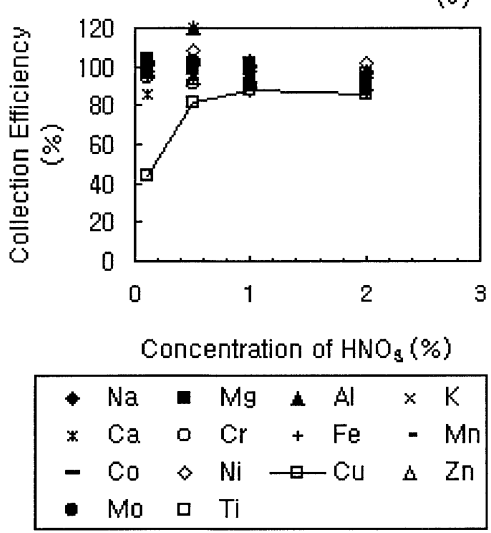

(b)

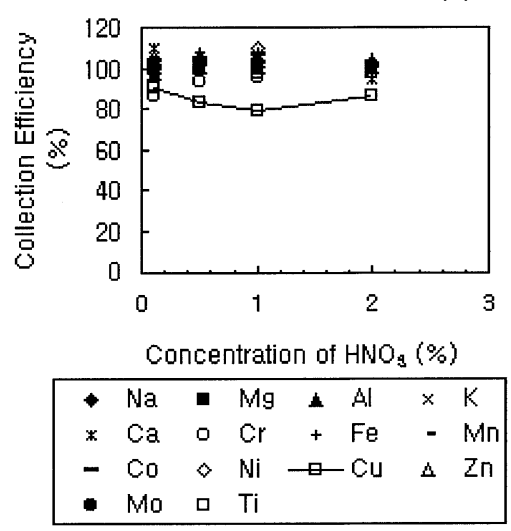

(d)

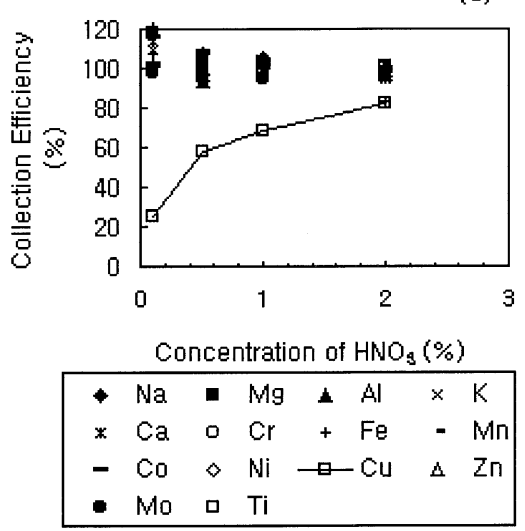

Fig. 2 Collection efficiency of metallic contaminants on (a) p-type, (b) $p^{+}$-type, (c) n-type and (d) $\mathrm{n}^{+}$-type silicon surfaces by $\mathrm{HNO}_{3}$. Contaminated concentration: $1 \mathrm{ng}$ of each element.

The reaction where $\mathrm{Cu}$ ion in a solution is reduced by accepting electrons can be expressed by the following oxidation/reduction reaction equation:

$$
\mathrm{Cu}^{2+}+2 \mathrm{e}^{-} \Leftrightarrow \mathrm{Cu}, E^{0}=0.337 \text { (V vs. NHE). }
$$

A comparison of the $\mathrm{Cu}$ collection efficiency on p-type and $\mathrm{p}^{+-}$ type silicon surfaces is shown in Fig. 3. In the case of the p-type silicon surface, electrons released by the oxidation of silicon can give rise to a reduction of the $\mathrm{Cu}$ ion. The $\mathrm{Cu}$ collection efficiency thus decreased as the concentration of $\mathrm{HNO}_{3}$ was decreased, because reduction of the $\mathrm{Cu}$ ion became dominant.

The $\mathrm{Cu}$ collection efficiency on a $\mathrm{p}^{+}$-type silicon surface can be explained based on the band model mentioned above. Electrons released by the oxidation of a silicon tunnel into the deeper region of crystal and recombine with holes. The reduction of $\mathrm{Cu}$ ion was restricted and the ionization of $\mathrm{Cu}$ was dominant in an oxidizing agent. Consequently, the $\mathrm{Cu}$ collection efficiency on the $\mathrm{p}^{+}$-type silicon surface was relatively good, even at a low concentration of $\mathrm{HNO}_{3}$, compared to the result of other types of substrates.

The $\mathrm{Cu}$ collection efficiency on $\mathrm{n}$ and $\mathrm{n}^{+}$-type silicon surfaces was similar to the result for a p-type silicon surface. From this result, it is assumed that the collection of $\mathrm{Cu}$ on $\mathrm{n}$ and $\mathrm{n}^{+}$-type silicon surfaces was interfered by the reduction of $\mathrm{Cu}$ ion at a low concentration of $\mathrm{HNO}_{3}$.

However, the $\mathrm{Cu}$ collection efficiency by $\mathrm{HNO}_{3}$ was less than $90 \%$ on four types of silicon wafers. This means that a small amount of $\mathrm{Cu}$ remained on the wafer surface, and $\mathrm{HNO}_{3}$ was not (a) $\mathrm{Si}+2 \mathrm{H}_{2} \mathrm{O} \rightleftarrows \mathrm{SiO}_{2}+4 \mathrm{H}^{+}+4 \mathrm{e}^{-} \quad \mathrm{E}^{0}=-0.857$ (V vs NHE)

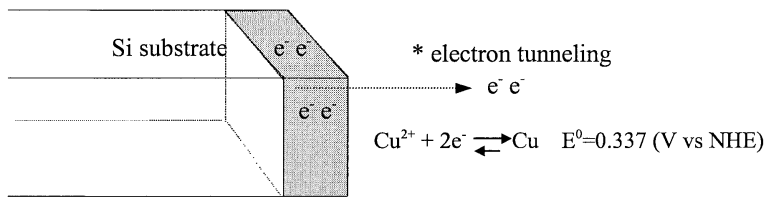

(b)

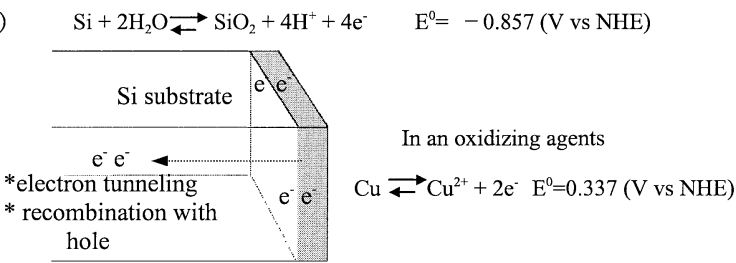

Fig. 3 Model of the $\mathrm{Cu}$ collection efficiency for (a) lightly and (b) heavily boron doped wafers.

suitable to collect the $\mathrm{Cu}$ contaminant completely. The collection efficiency of some elements had deviations between $80-120 \%$ regardless of the $\mathrm{HNO}_{3}$ concentration. These deviations are thought to be an experimental error caused by a poor sample treatment during intentional contamination, the drying process, and so on.

\section{Collection efficiency by $\mathrm{HF}$}

The collection efficiency of metallic contaminants by an HF 
(a)

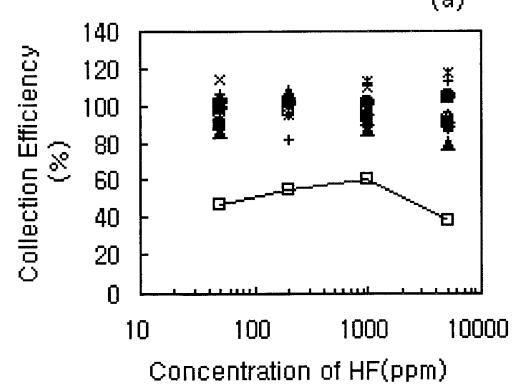

(c)

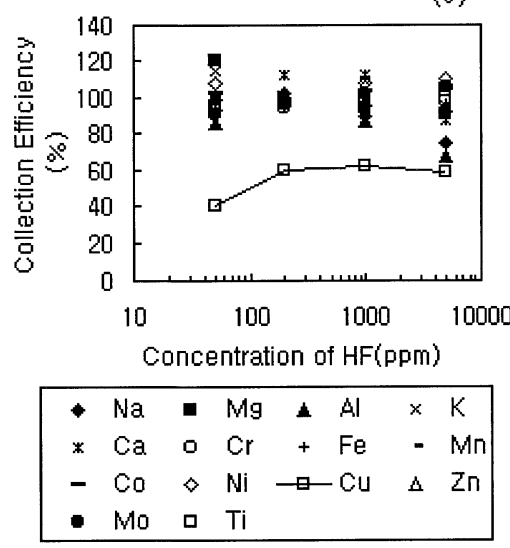

(b)

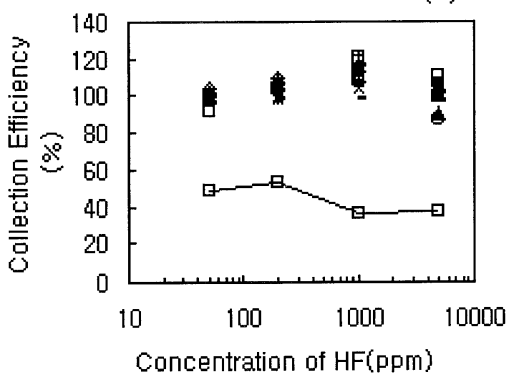

(d)

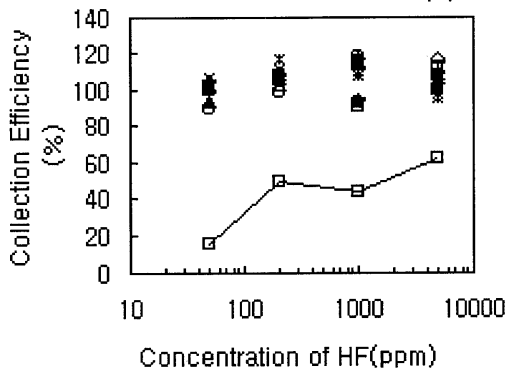

\begin{tabular}{|c|c|c|c|c|c|c|}
\hline$\bullet$ & $\mathrm{Na}$ & a & $\mathrm{Mg}$ & $A \quad \mathrm{Al}$ & $x$ & $K$ \\
\hline$x$ & $\mathrm{Ca}$ & 0 & $\mathrm{Cr}$ & $+\mathrm{Fe}$ & - & $\mathrm{Mn}$ \\
\hline - & $\mathrm{Co}$ & $\diamond$ & $\mathrm{Ni}$ & $\rightarrow \mathrm{Cu}$ & $\Delta$ & $Z n$ \\
\hline - & Mo & 口 & $\mathrm{Ti}$ & & & \\
\hline
\end{tabular}

Fig. 4 Collection efficiency of metallic contaminants on (a) p-type, (b) $\mathrm{p}^{+}$-type, (c) n-type and (d) $\mathrm{n}^{+}$-type silicon surfaces by HF. Contaminated concentration: $1 \mathrm{ng}$ of each element.

solution is shown in Fig. 4. A similar result was found on four types of wafers. The collection efficiency of 13 elements was good, and that of $\mathrm{Cu}$ was less than $70 \%$. It is thought that the collection of $\mathrm{Cu}$ was influenced by the reaction between silicon and HF. It is well known that $\mathrm{Cu}$ plates out on a silicon wafer surface in $\mathrm{HF} .{ }^{16,17} \quad \mathrm{SiO}_{2}$ of the silicon wafer surface is etched away by $\mathrm{HF}$ immediately. $\mathrm{Cu}$ contacts directly with bare silicon, resulting in an outplating of $\mathrm{Cu}$. For this reason, some of the $\mathrm{Cu}$ contaminant remained on the silicon surface in HF. Therefore, the collection efficiency of $\mathrm{Cu}$ was reduced in HF.

\section{Collection efficiency by a mixture of $\mathrm{HF}$ and $\mathrm{H}_{2} \mathrm{O}_{2}$}

The collection efficiency of metallic contaminants by a mixture of $\mathrm{HF}$ and $\mathrm{H}_{2} \mathrm{O}_{2}$ is shown in Fig. 5. The concentration of $\mathrm{H}_{2} \mathrm{O}_{2}$ was $1 \%$ and the concentration of $\mathrm{HF}$ was changed from $0.02 \%$ to $2 \%$. All of the metallic contaminants were collected effectively under all conditions. Moreover, there was no decrease in the $\mathrm{Cu}$ collection efficiency on $\mathrm{p}, \mathrm{n}$, and $\mathrm{n}^{+}$-type silicon surfaces. This is thought to have resulted because the oxidation of $\mathrm{Cu}$ was predominant in an $\mathrm{H}_{2} \mathrm{O}_{2}$-based mixture with a strong oxidizing agent, even when electrons released by the oxidation of silicon were supplied. It has been reported that a $\mathrm{Cu}$ contaminant was removed well in an $\mathrm{HF} / \mathrm{H}_{2} \mathrm{O}_{2}$ cleaning solution. ${ }^{18,19}$ It has also been discussed that a high oxidation power and passivation of a silicon surface by $\mathrm{H}_{2} \mathrm{O}_{2}$ are essential for removing a $\mathrm{Cu}$ contaminant on a silicon surface. It is considered that $\mathrm{Cu}$ on the silicon surface was collected very effectively in a mixture of $\mathrm{HF}$ and $\mathrm{H}_{2} \mathrm{O}_{2}$ for the same reason.

\section{Conclusions}

The collection efficiency of metallic contaminants on four different types of silicon wafers was investigated when VPDDC was employed as the sample-preparation procedure. Na, $\mathrm{Mg}, \mathrm{Al}, \mathrm{K}, \mathrm{Ca}, \mathrm{Cr}, \mathrm{Fe}, \mathrm{Mn}, \mathrm{Co}, \mathrm{Ni}, \mathrm{Cu}, \mathrm{Zn}, \mathrm{Mo}$ and $\mathrm{Ti}$ were contaminated on $\mathrm{p}, \mathrm{p}^{+}, \mathrm{n}$ and $\mathrm{n}^{+}$-type silicon wafer surfaces and collected into a collecting solution, which was $\mathrm{HNO}_{3}, \mathrm{HF}$ and a mixture of $\mathrm{HF}$ and $\mathrm{H}_{2} \mathrm{O}_{2}$, respectively. The collection efficiency of 13 elements, except for $\mathrm{Cu}$, was good in all of the studied collecting solutions. The collection efficiency of $\mathrm{Cu}$ was different, depending on the type of silicon wafer and collecting solution.

When $\mathrm{HNO}_{3}$ was used as the collecting solution, $\mathrm{Cu}$ on the $\mathrm{p}^{+}-$ type silicon surface was collected to near $90 \%$ in a low concentration of $\mathrm{HNO}_{3}$, contrary to the results of the other three types of silicon wafers. This result is considered to have been caused by restricting the reduction of $\mathrm{Cu}$ ion. Electrons that were released by the oxidation of silicon tunnel into a deeper region of the crystal and recombine with holes of the $\mathrm{p}^{+}$-type silicon wafer. Therefore, the reduction of $\mathrm{Cu}$ ion was restricted and the ionization of $\mathrm{Cu}$ was dominant in an oxidizing agent. The $\mathrm{Cu}$ collection efficiency, however, was less than $90 \%$ on four types of silicon wafers in $\mathrm{HNO}_{3}$. It is supposed that a small amount of $\mathrm{Cu}$ remains on the wafer surface in $\mathrm{HNO}_{3}$, which is not suitable for collecting all of the $\mathrm{Cu}$ contaminant. The $\mathrm{Cu}$ collection efficiency by HF was less than $70 \%$ for four types of silicon wafers. $\mathrm{HF}$ is also not suitable for $\mathrm{Cu}$ collection due to 

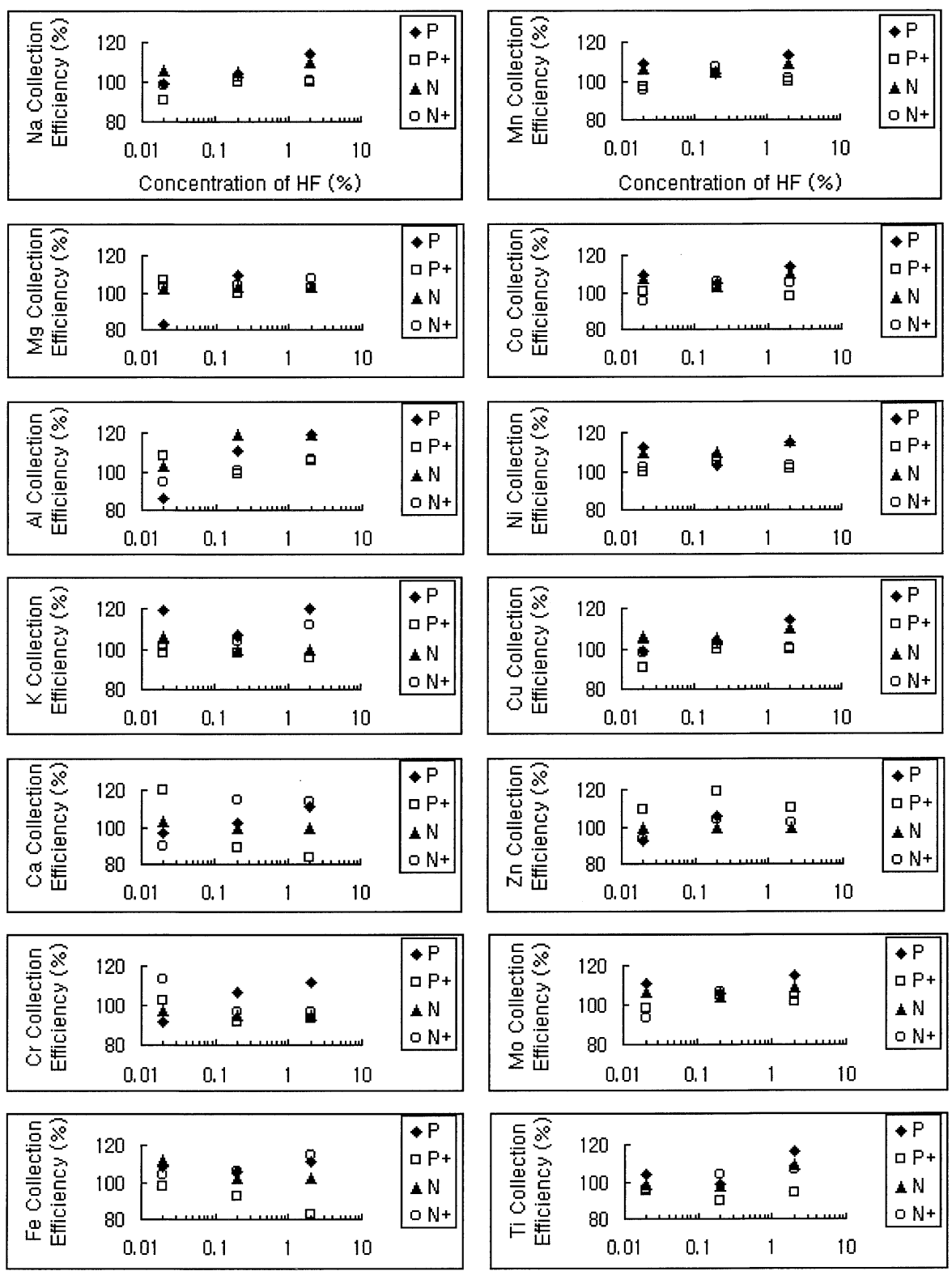

Fig. 5 Collection efficiency of metallic contaminants on $\mathrm{p}, \mathrm{p}^{+}, \mathrm{n}$ and $\mathrm{n}^{+}$-type silicon surfaces by a mixture of $\mathrm{HF}$ and $\mathrm{H}_{2} \mathrm{O}_{2}$. Concentration of $\mathrm{H}_{2} \mathrm{O}_{2}: 1 \%$; contaminated concentration: 1 ng of each element.

the deposition of $\mathrm{Cu}$ in $\mathrm{HF}$.

All of the elements including $\mathrm{Cu}$ were collected very effectively by a mixture of $\mathrm{HF}$ and $\mathrm{H}_{2} \mathrm{O}_{2}$. It is considered that the mixture of $\mathrm{HF}$ and $\mathrm{H}_{2} \mathrm{O}_{2}$ provided sufficient oxidation power to ionize the metallic contaminants and to prevent the deposition of $\mathrm{Cu}$ by generating a continuous oxide layer on the silicon surface. It turned out that the mixture of $\mathrm{HF}$ and $\mathrm{H}_{2} \mathrm{O}_{2}$ is the most effective way to collect metallic contaminants on a silicon wafer surface, regardless of the dopant concentration and the type of substrate.

\section{References}

1. W. Kern, in "Handbook of Semiconductor Wafer Cleaning Technology", ed. W. Kern, 1992, Noyes Publications, Park Ridge, 8.
2. W. Kern, in "Handbook of Semiconductor Wafer Cleaning Technology", ed. W. Kern, 1992, Noyes Publications, Park Ridge, 596.

3. H. Nagasawa and M. Enomoto, Bunseki Kagaku, 1997, 46, 375.

4. L. H. Hall, J. A. Sees, and B. L. Schmidt, Surf. Interface Anal., 1996, 24, 511.

5. R. S. Hockett, in "Handbook of Semiconductor Wafer Cleaning Technology", ed. W. Kern, 1992, Noyes Publications, Park Ridge, 584.

6. A. Shimazaki, H. Hiratsuka, Y. Matsushita, and S. Yoshii, Extended Abstracts of the 16th Conference on Solid State Devices and Materials, 1984, 281.

7. Y. Tanizoe, S. Sumita, M. Sano, N. Fujino, and T. Shiraiwa, Bunseki Kagaku, 1989, 34, 177.

8. M. Takenaka, Y. Yamada, M. Hayashi, H. Omori, S. Ito, and A. Okada, Bunseki Kagaku, 1997, 46, 743. 
9. G. Settembre and E. Debrah, Micro, 1998, 16, 79.

10. K. Fujiwara, Y. Toumori, H. Mitsumata, M. Inada, and T. Nakahara, Bunseki Kagaku, 1999, 48, 681.

11. M. Yamagami, M. Nonoguchi, T. Yamada, T. Shoji, T. Utaka, Y. Mori, S. Nomura, K. Taniguchi, H. Wakata, and S. Ikeda, Bunseki Kagaku, 1999, 48, 1005.

12. R. S. Hockett, Anal. Sci., 1995, 11, 511.

13. S. Pahike, L. Kotz, T. Ehmann, P. Eichinger, and A. Huber, in "Proceedings of the Eighth International Symposium on Silicon Materials Science and Technology", ed. H. R. Huff, H. Ysuya, and U. Gösele, 1998, ECS, San Diego, California, 1524 - 1540.

14. H. Morinaga, M. Suyama, M. Nose, S. Verhaverbeke, and T. Ohmi, IEICE TRANS. ELECTRON., 1996, E79C, 343.

15. H. Seidel, L. Csepregi, A. Heuberger, and H. Baumgartel,
J. Electrochem. Soc., 1993, 137, 3626.

16. T. Ohmi, T. Imaoka, T. Kezuka, J. Takano, and M. Kogure, J. Electrochem. Soc., 1993, 140, 811.

17. H. Morinaga and T. Ohmi, in "Proceedings of the Fourth International Symposium on Cleaning Technology in Semiconductor Device Manufacturing", ed. R. E. Novak and J. Ruzyllo, 1995, ECS, Chicago, Illinois, 257 - 268.

18. V. Bertagna, F. Rouelle, and M. Chemla, Semicond. Sci. Technol., 1998, 13, 444

19. G. M. Choi, H. Morita, H. Morinaga, J. S. Kim, and T. Ohmi, in "Proceedings of the Sixth International Symposium on Cleaning Technology in Semiconductor Device Manufacturing", ed. T. Hattori, R. E. Novak, and J. Ruzyllo, 1999, ECS, Honolulu, 272 - 279. 